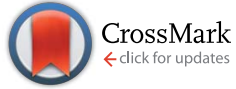

Cite this: Chem. Sci., 2016, 7, 6245

\title{
Preparation of an ion with the highest calculated proton affinity: ortho-diethynylbenzene dianion $\uparrow$
}

\author{
Berwyck L. J. Poad, ${ }^{\text {ab }}$ Nicholas D. Reed, ${ }^{\text {b }}$ Christopher S. Hansen, ${ }^{\text {b }}$ Adam J. Trevitt, ${ }^{\text {b }}$ \\ Stephen J. Blanksby, ${ }^{a}$ Emily G. Mackay, ${ }^{c}$ Michael S. Sherburn, ${ }^{c}$ Bun Chan t $^{d}$ \\ and Leo Radom ${ }^{\text {d }}$
}

Owing to the increased proton affinity that results from additional negative charges, multiply-charged anions have been proposed as one route to prepare and access a range of new and powerful "superbases". Paradoxically, while the additional electrons in polyanions increase basicity they serve to diminish the electron binding energy and thus, it had been thought, hinder experimental synthesis. We report the synthesis and isolation of the ortho-diethynylbenzene dianion (ortho-DEB ${ }^{2-}$ ) and present observations of this novel species undergoing gas-phase proton-abstraction reactions. Using a theoretical model based on Marcus-Hush theory, we attribute the stability of ortho-DEB ${ }^{2-}$ to the presence of a barrier that prevents spontaneous electron detachment. The proton affinity of $1843 \mathrm{~kJ}$ $\mathrm{mol}^{-1}$ calculated for this dianion superbase using high-level quantum chemistry calculations significantly exceeds that of the lithium monoxide anion, the most basic system previously prepared. The orthodiethynylbenzene dianion is therefore the strongest base that has been experimentally observed to date.

Received 20th April 2016

Accepted 17th June 2016

DOI: $10.1039 / c 6 s c 01726 f$

www.rsc.org/chemicalscience

solvent interaction, provides an ideal way to investigate the

\section{Introduction}

Exploration of the fundamental thermochemistry of acids and bases informs our understanding of chemical transformations and can drive innovation in the design of new reactions and reagents. ${ }^{1-3}$ The hydroxide anion has the largest proton affinity possible in an aqueous environment, since any base with a larger $\mathrm{PA}$ will abstract a proton from $\mathrm{H}_{2} \mathrm{O}\left(\mathrm{PA}\left[\mathrm{OH}^{-}\right]=1633.14\right.$ $\left.\pm 0.04 \mathrm{~kJ} \mathrm{~mol}^{-1}\right){ }^{4}$ To generate stronger bases in solution, nonaqueous solvents are required. For example lithium diisopropylamide, which is often employed in organic synthesis as a deprotonating agent, must be used in an aprotic solvent such as tetrahydrofuran. ${ }^{5}$ Such extremely strong bases are referred to as superbases. ${ }^{6}$ Owing to these environmental factors, investigation and comparison of the intrinsic basicity of compounds in solution is limited. Probing the reactivity of high proton affinity species in the gas phase, an environment free from any

${ }^{a}$ Central Analytical Research Facility, Institute for Future Environments, Queensland University of Technology, Brisbane, QLD 4001, Australia. E-mail: berwyck.poad@ qut.edu.au

${ }^{b}$ School of Chemistry, University of Wollongong, Gwynneville, NSW 2522, Australia

${ }^{c}$ Research School of Chemistry, Australian National University, Canberra, ACT 2601, Australia

${ }^{d}$ School of Chemistry, University of Sydney, Sydney, NSW 2006, Australia

$\dagger$ Electronic supplementary information (ESI) available: Synthesis of precursor compounds, detailed experimental and theoretical procedures, 3 supporting figures, 4 supporting tables, NMR spectra of synthesised compounds. See DOI: 10.1039/c6sc01726f

‡ Present address: Graduate School of Engineering, Nagasaki University, Bunko 1-14, Nagasaki 852-8521, Japan. fundamental basicity of these highly reactive systems. ${ }^{7}$

In the gas phase, the proton affinity of an anion is equivalent to the enthalpy of deprotonation $\left(\Delta_{\text {acid }} H_{298}\right)$ of the conjugate acid (i.e., $\mathrm{PA}\left[\mathrm{X}^{-}\right]=\Delta_{\text {acid }} H_{298}[\mathrm{XH}]$ ). The strongest base prepared to date is the lithium monoxide anion $\left(\mathrm{LiO}^{-}\right){ }^{8}$ With an estimated proton affinity of $1782 \pm 8 \mathrm{~kJ} \mathrm{~mol}^{-1}, \mathrm{LiO}^{-}$supplanted the methide anion $\left(\mathrm{CH}_{3}{ }^{-}\right)$at the top of the basicity scale in 2008, exceeding the proton affinity of the carbanion by approximately $40 \mathrm{~kJ} \mathrm{~mol}^{-1.4,9,10}$ More recently, computational studies have proposed extending this framework to even more basic ions such as $\mathrm{OLi}_{3} \mathrm{O}^{-} .{ }^{11}$ However no clear synthetic route to form these ions in the gas phase has been demonstrated. Anionic superbases such as $\mathrm{LiO}^{-}$and $\mathrm{CH}_{3}^{-}$necessarily satisfy two essential requirements: they are the conjugate bases of very weak gas-phase acids and their neutral radicals have low electron affinities (EAs). Multiply-charged anions can also fulfil these thermochemical requirements, as the gas-phase acidity of an anion is inherently low while the electron affinity of an anion (i.e., the affinity for addition of a second electron to produce a dianion) can be low or even negative. Despite their potential instability, such dianion systems have been observed because of a repulsive Coulomb barrier (RCB) that arises from the interaction between the local bound-potential of the functional group carrying the charge (e.g., a carboxylate group) and the repulsive Coulomb potential between like charges. ${ }^{12,13}$ This RCB can stabilise multiply-charged anions and, in some cases, allows for the generation and isolation of polyanions despite their negative electron binding energies. ${ }^{14,15}$ Based on these 
considerations, the 1,3-diethynylbenzene dianion (meta-DEB ${ }^{2-}$ ) was postulated to be a gas-phase superbase with a calculated PA of $1796.6 \mathrm{~kJ} \mathrm{~mol}^{-1}$, approximately $15 \mathrm{~kJ} \mathrm{~mol}^{-1}$ greater than that of the lithium monoxide anion. ${ }^{8}$ Thus far, no experimental studies have been reported on this gas-phase dianion presumably due to the expectation that Coulomb repulsion between the proximate negative charges would destabilise the dianion and thus pose a challenge to its generation and isolation.

In this article, we outline the synthesis of $m e t a-\mathrm{DEB}^{2-}$ in the gas phase along with the isomeric 1,2- and 1,4-diethynylbenzene dianions (ortho- and para- $\mathrm{DEB}^{2-}$, respectively). Observation of proton-transfer reactions between these dianions and a number of weak acids demonstrates their behaviour as gas-phase bases. The calculated proton affinity of each of the $\mathrm{DEB}^{2-}$ isomers exceeds that of the lithium monoxide anion, with ortho- $\mathrm{DEB}^{2-}$ representing the strongest gas-phase base synthesised to date.

\section{Results and discussion}

Synthesis of the ortho- $\mathrm{DEB}^{2-}$ dianion at a mass-to-charge ratio $(\mathrm{m} / \mathrm{z})$ of 62 was performed using tandem mass spectrometry in a linear quadrupole and followed the process outlined in Scheme 1 and Fig. 1. Negative ion electrospray ionisation of the diacid precursor generated the dicarboxylate dianion $(\mathrm{m} / \mathrm{z} 106)$, which was mass-selected and subjected to successive collisional activation steps to remove the carboxylate groups while retaining both charges. Such decarboxylation processes that are accompanied by retention of charge have previously been noted for several organolithium compounds. ${ }^{\mathbf{8} 16}$ The same method was deployed successfully for the generation of both meta- and para$\mathrm{DEB}^{2-}$, using the appropriate isomeric diacid precursor. In addition to the $\mathrm{DEB}^{2-}$ dianion $(\mathrm{m} / z$ 62) and its associated protontransfer product $(\mathrm{m} / \mathrm{z} 125)$ observed in Fig. $1 \mathrm{c}$, the main product ions following the final collisional activation step arise from loss of $\mathrm{CO}_{2}$ and loss of an electron from $\mathrm{m} / \mathrm{z} 84(\mathrm{~m} / \mathrm{z} 124)$, accompanied by a small amount of $\mathrm{C}_{2}$ loss from this ion $(\mathrm{m} / \mathrm{z} 100)$.

Decarboxylation of carboxylate anions upon collisioninduced dissociation has previously been demonstrated as an effective means to prepare regiospecific anions in the gas phase. ${ }^{17}$ Such precedent strongly suggests that regiochemistry of the three $m / z 62$ dianions is retained from their precursor

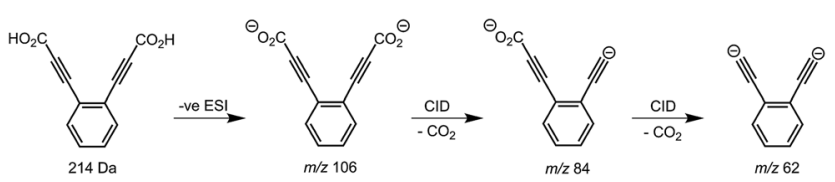

Scheme 1 Gas-phase synthesis of the ortho-DEB isomer. Negative ion electrospray ionisation produces the dicarboxylate dianion $(\mathrm{m} / \mathrm{z}$ 106). Subjecting this ion to successive stages of collisional activation results in the loss of two carbon dioxide molecules, with retention of both negative charges, yielding the ortho-DEB ${ }^{2-}$ dianion $\left(\mathrm{m} / \mathrm{z}\right.$ 62). Synthesis of the meta- and para-DEB ${ }^{2-}$ isomers proceeds in an analogous manner, using the appropriate diacid precursor.

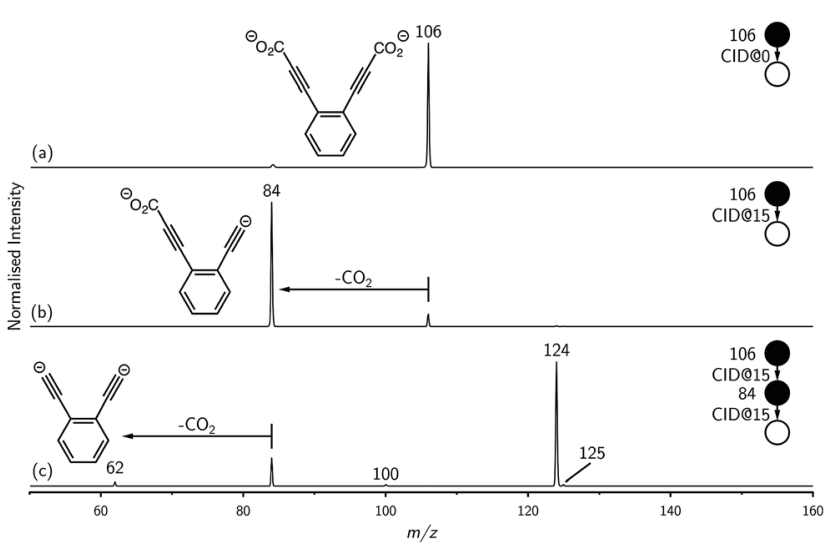

Fig. 1 Mass spectra illustrating the synthesis of the ortho-DEB dianion base. The mass-isolated dicarboxylate anion at $m / z 106$ (a) is observed to decarboxylate under CID to yield $\mathrm{m} / \mathrm{z} 84$ (b). Subsequent isolation and activation of this $\mathrm{m} / \mathrm{z} 84$ ion yields a second decarboxylation product at $m / z 62$ and associated reaction products (c). The meta- and para-DEB dianions were synthesised using the same approach.

diacids (i.e., ortho, meta and para-DEB ${ }^{2-}$ ). This is strongly supported by the differences in product ions and product ion abundances observed in the mass spectra at each step of the gas-phase preparation ( $c f$. ortho-DEB ${ }^{2-}$ in Fig. 1 and para-DEB ${ }^{2-}$ in ESI Fig. S1 $\dagger$ ). Moreover, the pseudo first-order decay of each of the $\mathrm{m} / \mathrm{z} 62$ ion populations is consistent with only a single isomer in each instance (Fig. 2). Full experimental

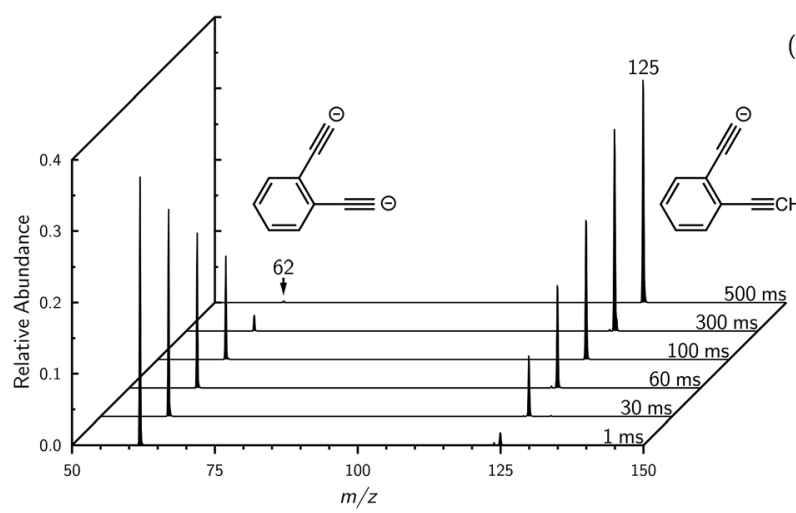

(a)

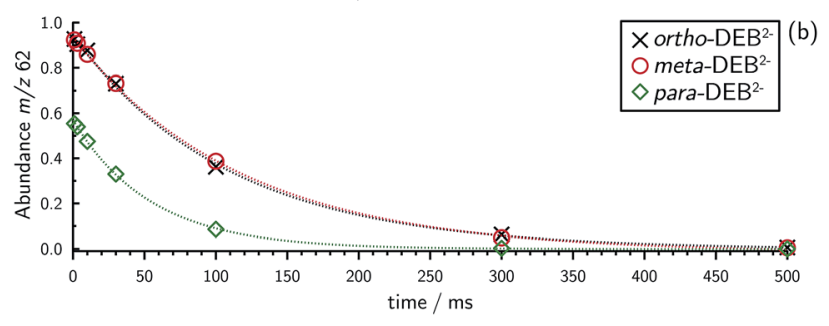

Fig. 2 (a) Evidence for proton abstraction by ortho-DEB ${ }^{2-}$. Mass spectra acquired by isolating ortho-diethynylbenzene dianion $(\mathrm{m} / \mathrm{z} 62)$ and monitoring the production of the proton-transfer product $(\mathrm{m} / \mathrm{z} 125)$ for increasing trapping times in the presence of background water show that the ion signal intensity growth for the proton-transfer product is clearly coupled to the decay of the dianion superbase ion signal. (b) Decay plots showing the decrease in integrated ion signal intensity with increased trapping time for $\mathrm{m} / \mathrm{z} 62$ for all three $\mathrm{DEB}^{2-}$ dianions. 
details, including preparation of the diacid precursors, are presented in the ESI. $\dagger$

Mass selection allowed isolation of the ortho- $\mathrm{DEB}^{2-}$ dianion within the ion trap and an investigation of its fate over time. Interrogation of the contents of the ion trap at times ranging from 1-500 ms showed a decrease in the abundance of ortho-DEB ${ }^{2-}$ at $m / z \quad 62$ and an associated increase in a product ion at $m / z 125$ (Fig. 2). This product arises from protonation of the dianion, most likely from background water present within the instrument. Proton transfer from water to the dianion was confirmed by leaking deuterated water into the ion trap. Mass spectra acquired following isolation of each of the three isomeric dianions and storage in the presence of $\mathrm{D}_{2} \mathrm{O}$ for $1 \mathrm{~ms}$ are displayed in Fig. 3. These spectra show the isotopic shift of the ion resulting from the acid-base reaction from $\mathrm{m} / \mathrm{z} 125$ to $\mathrm{m} / \mathrm{z} 126$, while the presence of $\mathrm{m} / z 18\left(\mathrm{DO}^{-}\right)$is diagnostic of deuteron abstraction from the heavy water. Because the performance of the ion-trap mass spectrometer is diminished at very low $m / z($ i.e. $m / z<20)$, the intensity of the $m / z 18$ peak appears artificially reduced compared with the intensity of $m / z 126$ and consequently a robust comparison of the product ion abundances is not possible. The presence of the $\mathrm{m} / \mathrm{z} 125$ ion in all spectra is evidence of proton abstraction from unlabelled water and other background gases present in the instrument.

For ortho- and meta-DEB ${ }^{2-}$ (Fig. $3 \mathrm{a}$ and b), proton or deuteron abstraction was the only process observed. For para$\mathrm{DEB}^{2-}$ (Fig. 3c), a product ion arising from electron loss was also detected at $m / z$ 124. This difference in the para- $\mathrm{DEB}^{2-}$ spectrum compared with that of the other two isomers can be rationalised by considering the calculated relative vertical detachment energies of the three dianions (i.e., $\operatorname{VDE}\left[\mathrm{DEB}^{2-}\right]$ ) and adiabatic electron affinities of the corresponding singlycharged radical anions (i.e., $\mathrm{AEA}\left[\mathrm{DEB}^{\circ-}\right]$ ). Using a relation derived from Marcus-Hush theory, the RCB height can be estimated from the calculated AEA and VDE values according to eqn (1). ${ }^{18}$

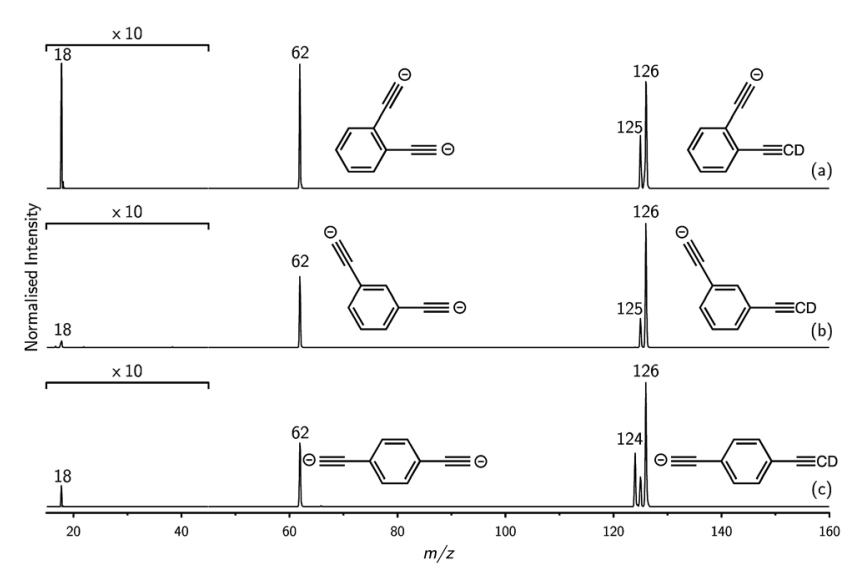

Fig. 3 Comparison of the reactivity of (a) ortho-, (b) meta- and (c) para-DEB $\mathrm{m} / \mathrm{z} 62$ isomers towards $\mathrm{D}_{2} \mathrm{O}$. The presence of $\mathrm{m} / \mathrm{z} 18\left(\mathrm{DO}^{-}\right)$ and $m / z 126\left(D^{2-}+D^{+}\right)$are indicative of deuteron abstraction from $\mathrm{D}_{2} \mathrm{O}$. Note that the region from $\mathrm{m} / \mathrm{z} 15-45$ has been magnified by a factor of 10. Reaction time is $1 \mathrm{~ms}$.

$$
\Delta G^{*}=\frac{\lambda}{4}\left(1+\frac{\Delta G^{\circ}}{\lambda}\right)^{2}
$$

If we interpret $\Delta G^{*}$ as the energy barrier for electron detachment, the reorganisation energy $\lambda$ as the energy difference between the VDE and AEA, and $\Delta G^{\circ}$ as the AEA, an estimate of the RCB height can be ascertained from the computed minimum energy structures of diethynylbenzene as both singlyand doubly-charged anions. The results, compiled in Table 1, show a negative AEA for both ortho- and para-DEB ${ }^{--}$, suggesting that only the meta- $\mathrm{DEB}^{2-}$ dianion is thermodynamically stable with respect to electron detachment. For the three dianions, however, electron ejection is inhibited by RCBs of 11.1 (ortho), 52.7 (meta) and 1.9 (para) $\mathrm{kJ} \mathrm{mol}^{-1}$. These barrier heights, calculated from eqn (1), are consistent with the analytical determination of barrier heights obtained using a rectilinear projection of the singly- and doubly-charged anion geometries (see Fig. 4 and ESI Table S1†). The presence of such barriers provides a rationalisation for the ability to prepare and isolate the $\mathrm{DEB}^{2-}$ dianions within the mass spectrometer despite the negative electron binding energies for two of the isomers. Furthermore, the low RCB barrier height for para- $\mathrm{DEB}^{2-}$ is consistent with the observed formation of the singly-charged para-DEB ${ }^{--}$radical anion $(m / z 124$ in Fig. 3c) for this isomer, with the $1.9 \mathrm{~kJ} \mathrm{~mol}^{-1}$ barrier to electron loss able to be surmounted at the $\sim 310 \mathrm{~K}$ temperature in the ion trap. ${ }^{19}$

The demonstration that the $\mathrm{DEB}^{2-}$ isomers can deprotonate water indicates that they have a PA in excess of $\mathrm{HO}^{-}$, but does not quantify their strength. Just how strong are these dianion bases? Proton abstraction from weaker acids was investigated and ion-molecule reactions of $\mathrm{DEB}^{2-}$ dianions with benzene (ESI Fig. S2 $\dagger$ ) show the proton-transfer product at $m / z 125$ for all isomers along with the phenide ion at $m / z 77\left(\mathrm{C}_{6} \mathrm{H}_{5}{ }^{-}\right)$. These results provide experimental evidence that the $\mathrm{DEB}^{2-}$ isomers are capable of deprotonating benzene and thus have proton affinities in excess of $\mathrm{PA}\left[\mathrm{C}_{6} \mathrm{H}_{5}{ }^{-}\right]=1678.7 \pm 2.1 \mathrm{~kJ} \mathrm{~mol}^{-1} \cdot{ }^{4}$ For both $\mathrm{D}_{2} \mathrm{O}$ and $\mathrm{C}_{6} \mathrm{H}_{6}$, the reactivity observed for ortho-DEB ${ }^{2-}$ far

Table 1 Computed G4(MP2)-6X proton affinities (PA) at $298 \mathrm{~K}$ along with vertical detachment energies (VDE), adiabatic electron affinities (AEA) and Repulsive Coulomb Barrier (RCB) heights for the three isomeric diethynylbenzene (DEB) dianions. Corresponding values for $\mathrm{LiO}^{-}, \mathrm{CH}_{3}^{-}$and $\left[\mathrm{C}_{2}-\mathrm{CH}_{2}-\mathrm{C}_{2}\right]^{2-}$ are provided for comparison

\begin{tabular}{|c|c|c|c|c|}
\hline Species & $\mathrm{PA} / \mathrm{kJ} \mathrm{mol}^{-1}$ & $\begin{array}{l}\mathrm{VDE} / \\
\mathrm{kJ} \mathrm{mol}^{-1}\end{array}$ & $\begin{array}{l}\mathrm{AEA}^{a} / \\
\mathrm{kJ} \mathrm{mol}^{-1}\end{array}$ & $\begin{array}{l}\text { RCB height/ } \\
\mathrm{kJ} \mathrm{mol}^{-1}\end{array}$ \\
\hline$[\text { ortho-DEB }]^{2-}$ & 1843.3 & -25.9 & -41.0 & 11.1 \\
\hline$[\text { meta-DEB }]^{2-}$ & $1786.8^{b}$ & 47.5 & 36.8 & 52.7 \\
\hline$[\text { para-DEB }]^{2-}$ & 1780.7 & 11.3 & -5.5 & 1.9 \\
\hline $\mathrm{LiO}^{-}$ & $1777.7^{c}$ & 50.8 & 50.1 & - \\
\hline $\mathrm{CH}_{3}{ }^{-}$ & $1747.7^{d}$ & 40.7 & 6.8 & - \\
\hline$\left[\mathrm{C}_{2}-\mathrm{CH}_{2}-\mathrm{C}_{2}\right]^{2-}$ & 1888.1 & -28.7 & -77.1 & 4.2 \\
\hline
\end{tabular}

${ }^{a}$ The AEA values refer to the radical species with one less negative charge, e.g. [ortho-DEB] ${ }^{--b} \mathrm{~B} 3-\mathrm{LYP} / 6-311+\mathrm{G}(2 \mathrm{df}, 2 \mathrm{pd})$ value of $1797 \mathrm{~kJ}$ $\mathrm{mol}^{-1} \cdot{ }^{8}{ }^{c}$ Best theoretical estimate of $1782 \pm 8 \mathrm{~kJ} \mathrm{~mol}^{-1}{ }^{8}$ ${ }^{d}$ Experimental values $1744 \pm 12 \mathrm{~kJ} \mathrm{~mol}^{-1},{ }^{4,9} 1742.2 \pm 0.8 \mathrm{~kJ} \mathrm{~mol}^{-1}{ }^{10}{ }^{\circ}$ 

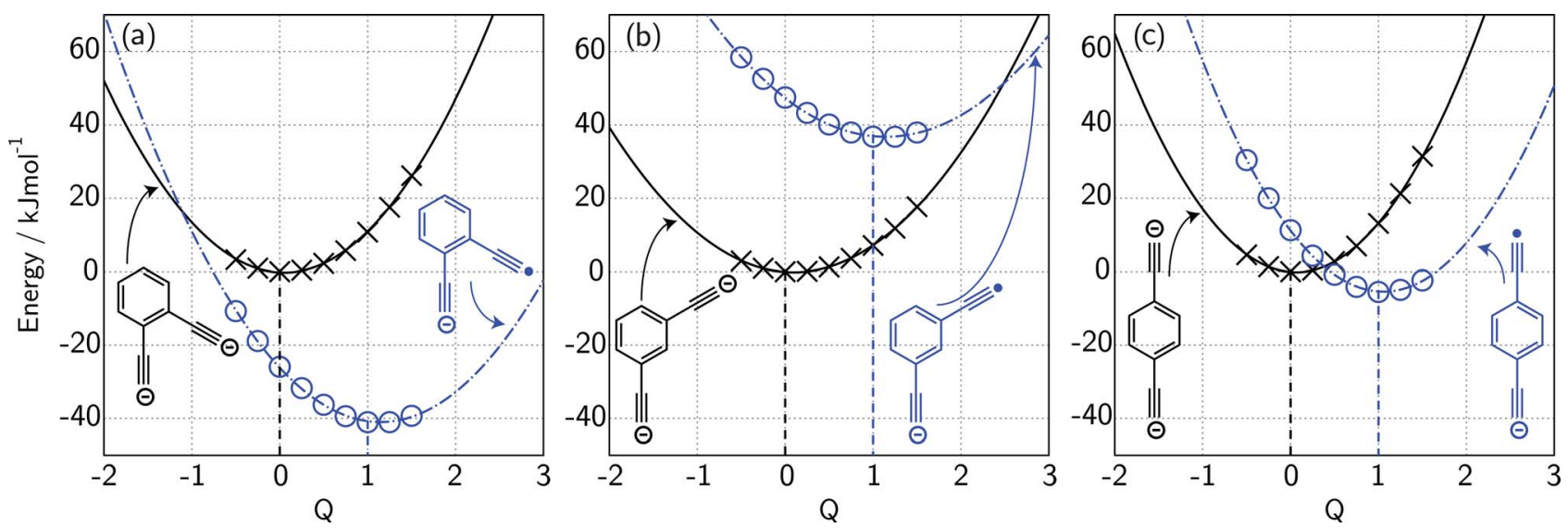

Fig. 4 Electronic potential energy surfaces calculated at the G4(MP2)-6X//BMK/6-31+G(2df,p) level for the dianion ( $x$ ) and monoanion radical (o) geometries for (a) ortho-DEB, (b) meta-DEB and (c) para-DEB. Geometries at various values of the parameter $Q$ correspond to a linear interpolation/extrapolation between the minimum energy dianion geometry $(Q=0)$ and the minimum energy monoanion radical geometry $(Q=1)$.

exceeds that of the other two isomers, reinforcing the heightened basicity of this species compared with meta- and para$\mathrm{DEB}^{2-}$, which are essentially the same at this level of ion signal. No proton-transfer reactions were observed between $\mathrm{DEB}^{2-}$ isomers and either dihydrogen or methane despite favourable thermodynamics for these processes, which may be attributed to the presence of a substantial barrier for proton abstraction from these acids (ESI Fig. S3 $\dagger$ ).

The G4(MP2)-6X method has been shown to have good performance for computing PAs $\left( \pm 2.8 \mathrm{~kJ} \mathrm{~mol}^{-1}\right)$ and benchmark calculations show good agreement in the case of strong gas-phase bases for which experimental PA data exist (Table S2 $\dagger$ ). ${ }^{20}$ Notwithstanding our experimental results, the computed G4(MP2)-6X proton affinities for all three $\mathrm{DEB}^{2-}$ dianions (Table 1) significantly exceed the experimentally benchmarked values for the methide anion $\left(\mathrm{PA}\left[\mathrm{CH}_{3}{ }^{-}\right]=1747.7\right.$ $\mathrm{kJ} \mathrm{mol}^{-1}$, see also Table S2 $\dagger$ ) as well as the proton affinity of lithium monoxide anion $\left(\mathrm{PA}\left[\mathrm{LiO}^{-}\right]=1777.7 \mathrm{~kJ} \mathrm{~mol}^{-1}\right)$ calculated at the same level of theory. Most significantly, ortho-DEB ${ }^{2-}$ has a computed proton affinity of $1843.3 \mathrm{~kJ} \mathrm{~mol}^{-1}$, making it the strongest base synthesised to date by some $65 \mathrm{~kJ} \mathrm{~mol}^{-1}$.

The thermochemical cycle of eqn (2) shows that the proton affinity of acetylide anions can be related to the homolytic bond dissociation enthalpy (BDE) of the $\mathrm{C}-\mathrm{H}$ bond and the AEA of the corresponding radical by the ionisation energy of a hydrogen atom $(\mathrm{IE}[\mathrm{H}]){ }^{21}$

$$
\mathrm{PA}\left[\mathrm{RC} \equiv \mathrm{C}^{-}\right]=\mathrm{BDE}[\mathrm{RC} \equiv \mathrm{C}-\mathrm{H}]+\mathrm{IE}[\mathrm{H}]-\mathrm{AEA}\left[\mathrm{RC} \equiv \mathrm{C}^{*}\right]
$$

It follows that the proton affinity of the diethynyl dianions is enhanced by the large, negative AEA of the corresponding radical anions. This effect of Coulombic repulsion on the AEA can be observed for the homologous series of model diethynyl dianions of the form $\left[\mathrm{C}=\mathrm{C}-\left(\mathrm{CH}_{2}\right)_{n}-\mathrm{C}=\mathrm{C}\right]^{2-}(n=1-4)$ (see ESI Table S3 $\dagger$ ). As the charged moieties are progressively brought closer together, resulting in an increase in the Coulombic repulsion within the dianions, computed electron affinities for the $\left[\mathrm{C}=\mathrm{C}-\left(\mathrm{CH}_{2}\right)_{n}-\mathrm{C}=\mathrm{C}\right]^{\cdot-}$ radical anions decrease from
$+86.1 \mathrm{~kJ} \mathrm{~mol}^{-1}(n=4)$ to $+1.4 \mathrm{~kJ} \mathrm{~mol}^{-1}(n=2)$ before returning large negative values when only a single methylene separates the two acetylide groups: $-77.1 \mathrm{~kJ} \mathrm{~mol}^{-1}(n=1)$. The decrease in AEA is accompanied by a concomitant increase in the proton affinity for the $\left[\mathrm{C}=\mathrm{C}-\left(\mathrm{CH}_{2}\right)_{n}-\mathrm{C}=\mathrm{C}\right]^{2-}$ dianion from 1775.4 $(n=4)$ through to $1888.1 \mathrm{~kJ} \mathrm{~mol}^{-1}(n=1)$. While the proton affinity can be enhanced by bringing the like charges together, synthesis and isolation of a dianion superbase requires an RCB sufficient to prevent electron detachment. The simple formalism of eqn (1) predicts that when $n=1$ the RCB is very low $\left(4.2 \mathrm{~kJ} \mathrm{~mol}^{-1}\right)$, suggesting that, like para- $\mathrm{DEB}^{2-}(\mathrm{RCB}=1.9$ $\mathrm{kJ} \mathrm{mol}^{-1}$, Table 1 ), the spontaneous loss of an electron is likely at room temperature.

\section{Conclusions}

To prepare superbasic dianions, the lowered electron affinity of the multiply-charged anion must be balanced against the stabilising effect of the repulsive Coulomb barrier. The model proposed here indicates that it is possible to estimate the stability of a multiply-charged anion with respect to electron detachment, based solely on the computed energies of the dianion and the detached monoanion. Findings from this simple model system therefore suggest that the ortho-DEB ${ }^{2-}$ dianion occupies a somewhat privileged thermochemical position, possessing both a large, negative AEA and an RCB sufficient to prevent electron ejection. This suggests that this dianion superbase, with a proton affinity of $1843.3 \mathrm{~kJ} \mathrm{~mol}^{-1}$, may be difficult to displace from its position atop the gas-phase basicity scale.

\section{Experimental}

\section{Synthetic methods}

Full synthetic details, including NMR and mass spectra for all compounds synthesised, are provided in the ESI. $\dagger$ Briefly, the regioisomeric dicarboxylic acid precursors ${ }^{22}$ to the DEB anions were each prepared using a three-step sequence from the 
corresponding di-aldehyde. Thus, a two-fold Corey-Fuchs alkyne synthesis, ${ }^{23}$ involving firstly, Ramirez olefination ${ }^{24}$ to the bis-dibromoalkenes, then treatment with $n$-BuLi and in situ quenching of the double acetylide species with chloromethylformate gave the di-esters. Finally, ester hydrolysis gave the di-carboxylic acids.

\section{Mass spectrometry}

The dianions were synthesised by electrospray ionisation of a methanolic solution of 3,3'-(phenylene)dipropiolic acid, basified with aqueous ammonia to aid deprotonation. Mass spectra were acquired using a dual linear quadrupole ion-trap mass spectrometer (LTQ Velos Pro, Thermo Scientific, San Jose CA). Precursor dianions at $\mathrm{m} / \mathrm{z} 106$ were isolated and collisionally activated (helium collision gas, 15\% normalised collision energy ${ }^{25}$ ), yielding the first decarboxylation product at $m / z 84$. The singly-decarboxylated product was subsequently re-isolated and collisionally activated ( $15 \%$ normalised collision energy) to yield the doubly-decarboxylated dianion at $m / z 62$ along with the singly-charged $\mathrm{CO}_{2}$ loss ion $\mathrm{m} / \mathrm{z} 124$ and a proton-transfer product $(\mathrm{m} / \mathrm{z} 125)$. This protocol was used for all three isomers. A minor product at $m / z 100$, most likely $\mathrm{C}_{2}$ loss from $\mathrm{m} / \mathrm{z} 124$, was observed for ortho-DEB ${ }^{2-}$ only.

Ion-molecule experiments were conducted by passing the ion-trap $\mathrm{He}$ buffer gas over a small amount of the neutral reagent (for $\mathrm{D}_{2} \mathrm{O}$ and $\mathrm{C}_{6} \mathrm{H}_{6}$ ). The vapour pressure of the neutral reagent at room temperature was sufficient to seed the helium buffer gas and was delivered to the high-pressure cell of the dual ion trap through the unmodified buffer gas inlet and split flow in the mass spectrometer. Reactions with gaseous reagents $\left(D_{2}\right.$ and $\mathrm{CD}_{4}$ ) were performed using a pre-made mixture of the deuterated reagents (both purchased from Sigma Aldrich, Castle Hill, NSW) in UHP helium (BOC Gases, North Ryde, NSW) and delivered into the ion trap through the ion trap buffer gas He inlet. The proportions of each gas mixture were $1.6 \%$ by volume in helium for $\mathrm{D}_{2}$ and $0.14 \%$ by volume in helium for $\mathrm{CD}_{4}$, yielding estimated number densities of $1.42 \times 10^{12}$ molecules per $\mathrm{cm}^{3}$ and $1.24 \times 10^{11}$ molecules per $\mathrm{cm}^{3}$, respectively, at the $\sim 2.5$ mTorr pressure within the ion trap. ${ }^{19}$ The use of $\mathrm{D}_{2} \mathrm{O}, \mathrm{D}_{2}$ and $\mathrm{CD}_{4}$ was necessitated by the presence of adventitious protonation reagents (such as $\mathrm{H}_{2} \mathrm{O}$ and $\mathrm{CH}_{3} \mathrm{OH}$ ) in the vacuum system.

\section{Theoretical methods}

Standard $a b$ initio molecular orbital theory and density functional theory calculations were carried out with Gaussian09. ${ }^{26}$ Gas-phase geometries of stationary points were obtained with the $\mathrm{BMK} / 6-31+\mathrm{G}(2 \mathrm{df}, \mathrm{p})$ procedure. ${ }^{27}$ Following each geometry optimisation, harmonic frequency analysis was carried out to confirm the nature of the stationary point as an equilibrium structure (all real frequencies) or a transition structure (one imaginary frequency). To obtain the zero-point vibrational energies (ZPVEs) and thermal corrections for enthalpies at $298 \mathrm{~K}\left(\Delta H_{298}\right)$ for the fully-optimised structures, we used BMK/6$31+\mathrm{G}(2 \mathrm{df}, \mathrm{p})$ harmonic vibrational frequencies and appropriate literature scale factors $(0.9770$ for ZPVE and 0.9627 for enthalpy correction). ${ }^{\mathbf{2 0 , 2 8}}$ For each of ortho-, meta- and para-diethynylbenzene, we have examined the potential energy surfaces for the mono- and di-anionic species along the path that connects the geometries of the two ions. This is accomplished using structures obtained through a linear combination of the optimised structures for the mono- and di-anions (see Fig. 4). Improved single-point energies were evaluated using the G4(MP2)-6X procedure for all structures. ${ }^{20}$ All relative energies are given in $\mathrm{kJ} \mathrm{mol}^{-1}$. Cartesian coordinates for all structures calculated are provided in the ESI as Table $\mathrm{S} 4 . \dagger$

\section{Acknowledgements}

The authors acknowledge funding from the Australian Research Council (DE120100467 and DP150101425) and the ARC Centre of Excellence for Free Radical Chemistry and Biotechnology (CE0561607), and generous grants of computing time from the National Computational Infrastructure (NCI) National Facility and Intersect Australia Ltd.

\section{Notes and references}

1 R. W. Alder, P. S. Bowman, W. R. S. Steele and D. R. Winterman, Chem. Commun., 1968, 723-724.

2 V. Raab, E. Gauchenova, A. Merkoulov, K. Harms, J. Sundermeyer, B. Kovačević and Z. B. Maksić, J. Am. Chem. Soc., 2005, 127, 15738-15743.

3 G. A. Olah, J. Org. Chem., 2005, 70, 2413-2429.

4 J. E. Bartmess, in NIST Chemistry WebBook, NIST Standard Reference Database Number 69, ed. P. J. Linstrom and W. G. Mallard, National Institute of Standards and Technology, Gaithersburg MD, 20899, retrieved April 132016.

5 D. B. Collum, A. J. McNeil and A. Ramirez, Angew. Chem., Int. Ed., 2007, 46, 3002-3017.

6 IUPAC, Compendium of Chemical Terminology, Blackwell Scientific Publications, Oxford, 2nd edn, the "Gold Book", 1997.

7 Z. B. Maksic, B. Kovacěvic and R. Vianello, Chem. Rev., 2012, 112, 5240-5270.

8 Z. Tian, B. Chan, M. B. Sullivan, L. Radom and S. R. Kass, Proc. Natl. Acad. Sci. U. S. A., 2008, 105, 7647-7651.

9 G. B. Ellison, P. C. Engelking and W. C. Lineberger, J. Am. Chem. Soc., 1978, 100, 2556-2558.

10 A. M. Oliveira, Y.-J. Lu, J. H. Lehman, P. B. Changala, J. H. Baraban, J. F. Stanton and W. C. Lineberger, J. Am. Chem. Soc., 2015, 137, 12939-12945.

11 A. K. Srivastava and N. Misra, Chem. Phys. Lett., 2016, 648, 152-155.

12 L.-S. Wang, C. F. Ding, X. B. Wang and J. B. Nicholas, Phys. Rev. Lett., 1998, 81, 2667-2670.

13 X. B. Wang, C. F. Ding and L.-S. Wang, Chem. Phys. Lett., 1999, 307, 391-396.

14 L.-S. Wang and X.-B. Wang, Nature, 1999, 400, 245-248.

15 M. K. Scheller, R. N. Compton and L. S. Cederbaum, Science, 1995, 270, 1160-1166.

16 M. M. Meyer, B. Chan, L. Radom and S. R. Kass, Angew. Chem., Int. Ed., 2010, 49, 5161-5164. 
17 Z. Tian and S. R. Kass, Chem. Rev., 2013, 113, 6986-7010. 18 G. Grampp, Angew. Chem., Int. Ed. Engl., 1993, 32, 691-693. 19 D. G. Harman and S. J. Blanksby, Org. Biomol. Chem., 2007, 5, 3495.

20 B. Chan, J. Deng and L. Radom, J. Chem. Theory Comput., 2011, 7, 112-120.

21 S. J. Blanksby and G. B. Ellison, Acc. Chem. Res., 2003, 36, 255-263.

22 R. Saravanakumar, B. Varghese and S. Sankararaman, CrystEngComm, 2009, 11, 337-346.

23 E. J. Corey and P. L. Fuchs, Tetrahedron Lett., 1972, 13, 37693772.

24 F. Ramirez, N. B. Desai and N. McKelvie, J. Am. Chem. Soc., 1962, 84, 1745-1747.

25 J. C. Schwartz and D. M. Taylor, US Pat., US6124591 A, 2000. 26 M. J. Frisch, G. W. Trucks, H. B. Schlegel, G. E. Scuseria, M. A. Robb, J. R. Cheeseman, G. Scalmani, V. Barone, B. Mennucci, G. A. Petersson, H. Nakatsuji, M. Caricato, X. Li, H. P. Hratchian, A. F. Izmaylov, J. Bloino, G. Zheng,
J. L. Sonnenberg, M. Hada, M. Ehara, K. Toyota, R. Fukuda, J. Hasegawa, M. Ishida, T. Nakajima, Y. Honda, O. Kitao, H. Nakai, T. Vreven, J. A. Montgomery Jr, J. E. Peralta, F. Ogliaro, M. J. Bearpark, J. Heyd, E. N. Brothers, K. N. Kudin, V. N. Staroverov, R. Kobayashi, J. Normand, K. Raghavachari, A. P. Rendell, J. C. Burant, S. S. Iyengar, J. Tomasi, M. Cossi, N. Rega, N. J. Millam, M. Klene, J. E. Knox, J. B. Cross, V. Bakken, C. Adamo, J. Jaramillo, R. Gomperts, R. E. Stratmann, O. Yazyev, A. J. Austin, R. Cammi, C. Pomelli, J. W. Ochterski, R. L. Martin, K. Morokuma, V. G. Zakrzewski, G. A. Voth, P. Salvador, J. J. Dannenberg, S. Dapprich, A. D. Daniels, Ö. Farkas, J. B. Foresman, J. V. Ortiz, J. Cioslowski and D. J. Fox, Gaussian09, Revision C01, 2009.

27 A. D. Boese and J. M. L. Martin, J. Chem. Phys., 2004, 121, 3405-3416.

28 J. P. Merrick, D. Moran and L. Radom, J. Phys. Chem. A, 2007, 111, 11683-11700. 